Purdue University

Purdue e-Pubs

2020

Time-Resolved Characterization of Microchannel Flow Boiling

During Transient Heating: Part 1 - Dynamic Response to a Single Heat Flux Pulse

T. A. Kingston

J. A. Weibel

S V. Garimella

Follow this and additional works at: https://docs.lib.purdue.edu/coolingpubs

This document has been made available through Purdue e-Pubs, a service of the Purdue University Libraries.

Please contact epubs@purdue.edu for additional information. 


\title{
Time-Resolved Characterization of Microchannel Flow Boiling During Transient Heating: Part 1 - Dynamic Response to a Single Heat Flux Pulse ${ }^{1}$
}

\author{
Todd A. Kingston ${ }^{2}$, Justin A. Weibel*, and Suresh V. Garimella ${ }^{3 *}$ \\ Cooling Technologies Research Center \\ School of Mechanical Engineering, Purdue University, West Lafayette, Indiana 47907 USA
}

\begin{abstract}
Microchannel flow boiling is an attractive approach for the thermal management of highheat-flux electronic devices that are often operated in transient modes. In Part 1 of this two-part study, the dynamic response of a heated $500 \mu \mathrm{m}$ channel undergoing flow boiling of HFE-7100 is experimentally investigated for a single heat flux pulse. Three heat flux levels exhibiting highly contrasting flow behavior under constant heating conditions are used: a low heat flux corresponding to single-phase flow $\left(15 \mathrm{~kW} / \mathrm{m}^{2}\right)$, an intermediate heat flux corresponding to continuous flow boiling $\left(75 \mathrm{~kW} / \mathrm{m}^{2}\right)$, and a very high heat flux which exceeds critical heat flux and would cause dryout if applied continuously $\left(150 \mathrm{~kW} / \mathrm{m}^{2}\right)$. Transient testing is conducted by pulsing between these three heat flux levels and varying the pulse duration. High-frequency measurements of heat flux, wall temperature, pressure drop, and mass flux are synchronized to high-speed flow visualizations to characterize the boiling dynamics during the pulses. At the onset of boiling, the dynamic response resembles that of an underdamped mass-spring-damper
\end{abstract}

1 Submitted for review to International Journal of Heat and Mass Transfer as Part 1 of two companion papers

2 Currently NRC/NRL Cooperative Research Associate, U.S. Naval Research Laboratory, Washington D.C.

3 Currently President, University of Vermont

* Corresponding authors

E-mail addresses: kingston@purdue.edu (T.A. Kingston), jaweibel@purdue.edu (J.A. Weibel),

sureshg@purdue.edu (S.V. Garimella) 
system subjected to a unit step input. During transitions between single-phase flow and timeperiodic flow boiling, the wall temperature temporarily over/under-shoots the eventual steady operating temperature (e.g., by up to $20^{\circ} \mathrm{C}$ ) thus demonstrating that transient performance can extend beyond the bounds of steady performance. It is shown that longer duration high-heat-flux pulses (up to $\sim 50 \%$ longer in some cases) can be withstood when the fluid in the microchannel is initial boiling, relative to if it is initially in the single-phase flow regime, despite being at an initially higher heat flux and wall temperature prior to the pulse.

Keywords: dynamic response, flow boiling, microchannel, heat flux pulse, transient heating

\section{Highlights}

- Microchannel flow boiling under transient heating conditions is studied experimentally.

- High-frequency sensor measurements are synchronized to flow visualizations.

- Heat flux is pulsed between 15,75 , and $150 \mathrm{~kW} / \mathrm{m}^{2}$ using a thin film heater.

- The dynamic response to a transient pulse is qualitatively similar to that of a spring-massdamper system.

- Heat flux pulses that induce/arrest boiling cause a temporary wall temperature over/under-shoot.

\section{Nomenclature}

$c_{p} \quad$ specific heat

D microchannel inside diameter

G mass flux

$h \quad$ heat transfer coefficient

$L_{c} \quad$ characteristic length

$\Delta p \quad$ pressure drop across the microchannel 


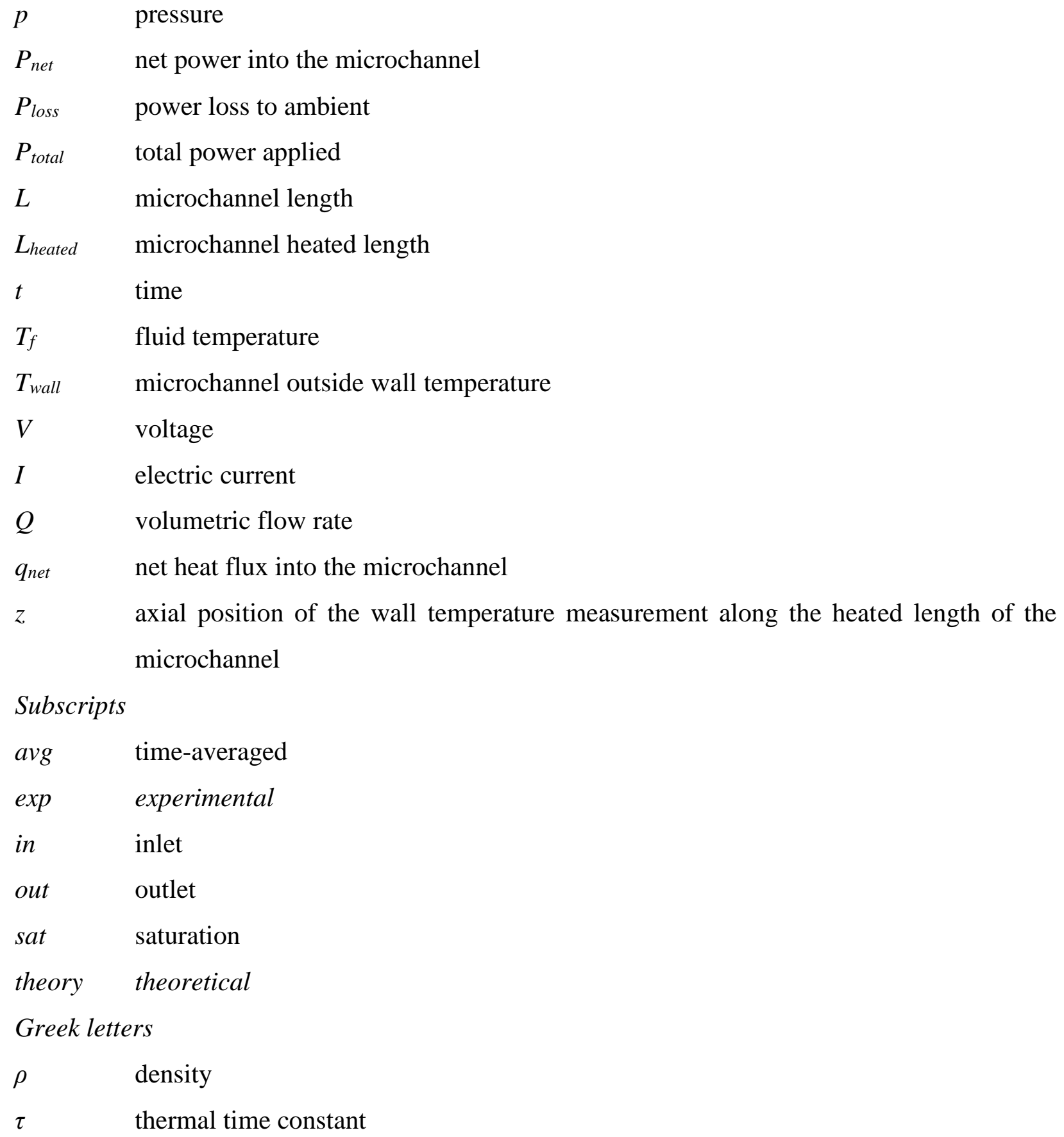

\section{Introduction}

Dissipation of high heat fluxes is a challenge facing a wide range of industries, including automotive, aerospace, electronics, and nuclear. Microchannel flow boiling, which exploits the latent heat of the fluid, has been identified as a promising thermal management solution because 
it features high heat transfer coefficients and low pumping power requirements while offering improved temperature uniformity compared to single-phase cooling strategies.

The vast majority of previous flow boiling studies have utilized time-averaged characterization techniques to quantify the thermal and hydrodynamic performance. While these efforts have provided valuable insight into characteristics such as the time-averaged heat transfer coefficient and critical heat flux, transient boiling phenomena remain less understood. Recently, the use of high-frequency measurement techniques has enabled time-resolved characterization of the boiling process under constant heating conditions. Rao et al. [1] fabricated a single-channel microdevice with thin-film thermistors to measure the local wall temperature, with high spatial and temporal resolution, synchronized to flow visualizations. The transient temperature signatures (recorded at 10-15 kHz) during constant heating conditions were correlated to twophase flow regimes. Zhu et al. [2] investigated temperature fluctuations in a parallel-channel two-phase heat sink induced by high-frequency flow oscillations using a $1 \mathrm{kHz}$ measurement rate. It was shown that the addition of hydrophilic surface structures on the interior bottom surfaces of the microchannels reduced the temperature oscillations relative to standard smooth surfaces. Kingston et al. $[3,4]$ used high-frequency $(2.5 \mathrm{kHz})$ thermal-fluidic measurements synchronized to high-speed flow visualization to study dynamic flow boiling instabilities in a microchannel subjected to constant heating conditions. A parametric study quantified the impact of operating conditions on the rapid-bubble-growth instability and the pressure drop instability. Bigham and Moghaddam [5, 6] used a microfluidic device capable of quantifying local heat fluxes with spatial and temporal resolution of $40-65 \mu \mathrm{m}$ and $50 \mu \mathrm{s}$, respectively, to identify the dominant transient heat transfer mechanisms during flow boiling. The local heat flux into the 
fluid was shown to vary in time due to local bubble dynamics despite a constant heat flux being applied to the device.

Developing an understanding of the transient heat transfer behavior during boiling is further complicated if the heating conditions vary in time. Many applications encounter transient operation resulting in a time-varying heat generation, such as central processing units (CPUs), radio-frequency power amplifiers, laser diodes, and avionics [7]. These thermal transients can have repercussions on device operation and result in poor performance, reduced reliability, and even device failure. For example, gallium nitride power amplifiers used in multifunctional radar systems often suffer from self-heating electrothermal 'memory effects' when switching between different coherent processing intervals, which lead to changes in the amplifier gain and insertion phase that negatively affect device performance [8]. Recent interest in 'embedded cooling' strategies that would embed coolant channels within the device, near the source of heat generation, can exacerbate the effects of transient heating conditions [9]. These heating transients can lead to flow boiling instabilities and oscillations, which have been shown to reduce the heat transfer coefficient [10-12] and critical heat flux [13].

To address these concerns, researchers have begun to study the transient temperature response at the onset of boiling when subjected to a single heat pulse. Basu et al. [14] performed an experimental study to identify parametric trends governing the transient wall temperature at the onset of HFE-7000 flow boiling through a microgap in response to a heat flux step change and single pulse from zero to various heat flux levels. The effects of mass flux, heat flux amplitude, and pulse duration were investigated. The onset of boiling and bubble dynamics were observed using high-speed flow visualization. At low heat fluxes, nucleation of discrete bubbles governed the heat transfer performance, whereas at high heat fluxes nucleation quickly led to a 
vapor film over the heater surface and a large temperature rise. Huang et al. [15] performed an experimental study to investigate the base temperature response of a multi-microchannel evaporator during heat flux step change from zero to a given level. The base temperature was measured using an infrared camera and was synchronized to high-speed flow visualizations. At the onset of boiling, the base temperature increased significantly, well above the steady wall temperature during constant heating conditions. However, reducing the inlet orifice width, heat flux magnitude, inlet subcooling, and outlet saturation temperature, or increasing the mass flux, decreased the maximum base temperature during this transient event. A large temperature increase at the onset of boiling for low flow rates was also observed by Kingston et al. [3]. Chen and Cheng [16] studied the flow boiling phenomena and surface temperature response of a microheater in a single microchannel subjected to a 2 ms-long heat pulse. The initially unpowered heater surface was activated and the temperature of the platinum microheater was synchronized to flow visualizations for various heat flux and mass flux combinations. For a given mass flux, nucleate boiling was the dominant heat transfer mechanism at low heat flux levels whereas film boiling dictated the performance at high heat flux levels. While these prior studies have successfully quantified the temperature response, the hydrodynamic response was not studied. Additionally, these prior studies have been solely focused on the onset of boiling. A thorough investigation into the coupled thermal-fluidic response of the flow boiling system at the onset and arrest of boiling and when boiling is already occuring in the channel is needed to provide a comprehensive understanding.

In this two-part study, the effects of transient heating conditions on microchannel flow boiling performance are investigated experimentally. Time-averaged data collected during constant heating conditions are used to first identify three different heat flux levels that exhibit 
highly contrasting flow behavior for which transient heating tests can be conducted. In Part 1, the dynamic thermal-fluidic response of the system to a single heat flux pulse is investigated both at the onset of boiling and with the channel initially boiling. The thermal-fluidic response is also investigated for pulses that arrest boiling. High-frequency sensor measurements of temperature and hydrodynamic signatures are synchronized to high-speed flow visualizations to enable first-of-their-kind time-resolved characterization during this transient event. In Part 2 [17], the flow boiling behavior is characterized during periodic heating pulses and the resulting thermal and hydrodynamic characteristics are investigated.

\section{Experimental methods}

\subsection{Test facility}

The custom-built experimental facility, schematically illustrated in Figure 1, is adapted from our previous flow boiling studies $[3,4,18]$, and uses a pressurized reservoir to deliver degassed, dielectric HFE-7100 liquid (Novec Engineered Fluid, 3M) to a single microchannel. The pressure difference between this reservoir and the ambient is used to generate an open-loop flow. This choice of boundary conditions enables the flow rate through the test-section microchannel to vary in time depending on the local thermal-fluidic behavior, as an individual channel would behave in a parallel-channel configuration [3]. The rigid reservoir is pressurized by boiling fluid using a submerged cartridge heater. A constant reservoir pressure is set and maintained by adjusting the cartridge heater power. 


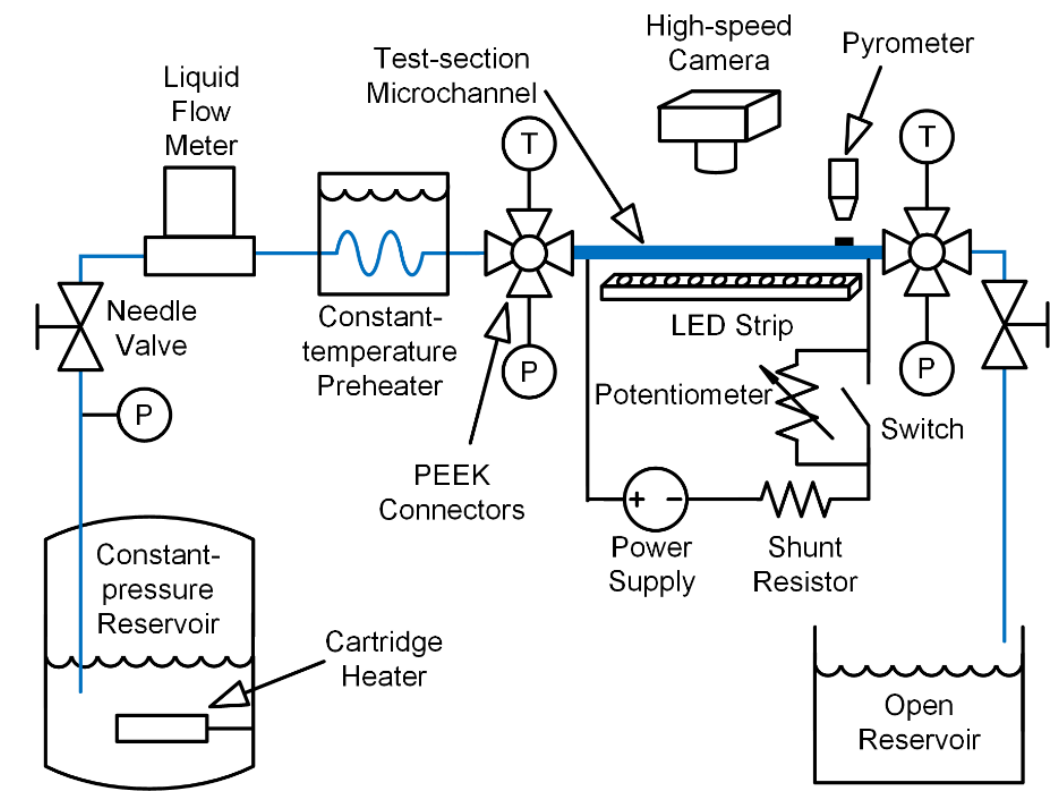

Figure 1. Schematic diagram of the experimental facility used to characterize flow boiling during transient heating conditions. A photograph of the test section is provided in Part 2 of this study [17].

Liquid is extracted from the reservoir through an internal dip tube. The liquid flow rate and the test section outlet saturation pressure are adjusted using a pair of needle valves, one upstream and one downstream of the test section. The liquid volumetric flow rate and temperature are measured using a liquid flow meter (LC-10CCM-D-EPDM, Alicat; accuracy of $\pm 1 \%$ full scale). The fluid is preheated to the desired inlet temperature immediately upstream of the test section, using a constant-temperature circulating bath. The inlet and outlet fluid temperatures are measured immediately upstream and downstream of the test section using small exposed-tip thermocouples (TMTSS-020E-6, Omega Engineering; accuracy of $\pm 0.5^{\circ} \mathrm{C}$ ) featuring a bead diameter of $\sim 250 \mu \mathrm{m}$, which enables dynamic changes in fluid temperatures to be measured. The pressures at the inlet and outlet of the microchannel are measured using separate pressure transducers (PX309-030G5V and PX309-015G5V, respectively, Omega 
Engineering; accuracy of $\pm 1 \%$ ). Short, rigid stainless steel tubes were used to connect the pressure transducers to the polyetheretherketone (PEEK) connectors to minimize damping and enable dynamic pressure fluctuations to be accurately measured. The pressure drop across the test section is taken as the difference between the inlet and outlet pressure measurements. The thermocouples and pressure transducers, in addition to the fluid inlet and outlet connections, are mounted to the PEEK connectors, as shown in Figure 1; the test-section microchannel is mounted horizontally between these connectors.

The circular cross-section microchannel is made of borosilicate glass (CV5070, VitroCom) with an inside diameter of $D=500 \mu \mathrm{m}$ and a wall thickness of $100 \mu \mathrm{m}$. The thin wall enables transient heating conditions to easily propagate to the coolant, as may occur in embedded two-phase heat sinks $[19,20]$. The outside surface of the microchannel has an approximately $100 \mathrm{~nm}$-thick layer of indium tin oxide (ITO). The ITO layer is optically transparent and electrically conductive, enabling visualization of the two-phase flow while subjected to uniform Joule heating. Power is supplied to the ITO coating using an adjustable DC power supply (XG $850 \mathrm{~W} 300 \mathrm{~V}-2.8 \mathrm{~A}$, Sorensen). The total heating power (which includes power loss to the ambient) applied to the test section is quantified by measuring the voltage drop across and current through the ITO microchannel coating; the current is obtained from a shunt resistor. A solid-state switch (PAA140, IXYS Corp.) is wired in parallel to a circuit of potentiometers (RJS10KE, RHS1K0E, RES100E; Ohmite) to allow active switching between two different power levels and fine adjustment of the magnitudes. The switch is activated by an output voltage signal from a high-frequency data acquisition (DAQ) unit (USB-6259, National Instruments) that is controlled using LabVIEW. Test-section heat flux, wall temperature, 
pressure drop, and mass flux measurements are obtained at $2.5 \mathrm{kHz}$ using the high-frequency DAQ unit.

The outside wall temperature of the microchannel is measured at a single fixed location using a pyrometer (CTfast LT25F, Optris) coupled to a focusing lens (ACCTCF, Optris). The pyrometer is focused on a black dot painted on the outside surface of the channel. Calibration of the pyrometer voltage output to the wall temperature is described in Ref. [18]. The axial position of the wall temperature measurement along the heated length of the microchannel is $z / L_{\text {heated }}$ $=0.91$; the heated length of the microchannel, $L_{\text {heated }}$, is $42 \mathrm{~mm}$.

The entire heated region of the microchannel is visualized from the top using a highspeed camera (VEO710L, Phantom) coupled to a macro lens (AF Micro-Nikkor, Nikon) using an image resolution of $1280 \times 120$ at $30,000 \mathrm{fps}$. The bottom side of the channel is uniformly backlit using a light-emitting diode (LED) strip. High-speed optical images are synchronized to heat flux, pressure drop, mass flux, and wall temperature measurements using a pulse generator (565, Berkeley Nucleonics Corp.) to simultaneously trigger the camera and high-frequency DAQ unit.

\subsection{Test procedure}

As described in Ref. [3], immediately prior to testing, the HFE-7100 fluid was degassed by vigorously boiling the liquid in the reservoir using the submerged cartridge heater. Noncondensable gases are expelled, while the HFE-7100 vapor is condensed back into the reservoir (Figure 1). Experiments were initiated by boiling the liquid in the reservoir until it reached a constant reservoir pressure of $190 \mathrm{kPa}$. Liquid flow was then initiated through the test section at a mass flux of $400 \mathrm{~kg} / \mathrm{m}^{2} \mathrm{~s}$ and a saturation pressure of $p_{\text {sat }}=114 \mathrm{kPa}$ at the outlet of the channel; this corresponds to an outlet saturation temperature of $T_{\text {sat }}=65^{\circ} \mathrm{C}$. The test facility features a 
constant pressure drop across the system, not a constant mass flux, and thus the mass flux through the microchannel can vary from the initial setting once boiling occurs and causes a change in the flow resistance. The constant-temperature bath setpoint was adjusted to heat the liquid to an inlet temperature of $T_{f, i n}=60^{\circ} \mathrm{C}$, resulting in an inlet liquid subcooling of $5{ }^{\circ} \mathrm{C}$, based on the outlet saturation temperature.

After establishing the desired flow conditions, two sets of tests were performed. First, constant heat flux was applied to the ITO-coating on the microchannel in increments, allowing for steady-state conditions to be achieved between each set point. At low heat flux conditions, the flow remained in a single phase and only sensor data were recorded. At heat flux levels resulting in boiling, sensor data and optical images were recorded. Sensor data and optical images were acquired for $12 \mathrm{~s}$ and the recorded data then averaged to produce time-averaged data. Next, transient heating tests were initiated. A single heat flux pulse was applied to the microchannel, defined in this study as a step change from one heat flux level to another for a fixed time duration followed by a step change back to the original heat flux level. The heat flux levels and pulse durations chosen for this study are discussed in Section 3.2 and summarized in Table 1. For these transient tests, sensor data and optical images were recorded $2 \mathrm{~s}$ prior to and $10 \mathrm{~s}$ after the start of the heat flux pulse.

\subsection{Data reduction}

A portion of the total power supplied to the ITO coating on the microchannel is lost to the ambient (i.e., not transferred to the fluid through the microchannel wall). This power loss is a function of the channel wall temperature and was calibrated after testing using the procedure described in Ref. [3]. A temperature-dependent power loss equation, $P_{l o s s}=0.0073 T_{\text {wall }}-$ 0.1854 , is obtained and had a coefficient of determination of $\mathrm{R}^{2}=0.97$. The instantaneous wall 
temperature during transient tests is used to quantify the power loss, resulting in the calculation of a time-varying power loss. The net power into the microchannel is calculated by subtracting the power loss from the total electric power supplied using $P_{\text {net }}=P_{\text {total }}-P_{\text {loss }}$; power is calculated using $P_{\text {total }}=V I$ where $V$ is the voltage applied to the test section and $I$ is the current through the test section.

The instantaneous heat flux into the test section is calculated using $q_{\text {net }}=P_{\text {net }} /(\pi D$ $\left.L_{\text {heated }}\right)$. The time-averaged heat transfer coefficient is calculated using $h_{\text {avg }}=q_{\text {net,avg }} /\left(T_{\text {wall,avg }}\right.$ $\left.T_{\text {ref,avg }}\right)$, where the time-averaged reference temperature $\left(T_{r e f, a v g}\right)$ is evaluated at the location of the wall temperature measurement $\left[\left(z / L_{\text {heated }}\right)=0.91\right]$. For single-phase flow, the time-averaged reference temperature is defined as the liquid temperature at this location assuming a linear increase in liquid temperature from the inlet to the outlet of the microchannel: $T_{\text {ref,avg }}=T_{f, \text { in }, \text { avg }}+$ $\left(z / L_{\text {heated }}\right)\left(T_{f, \text { out,avg }}-T_{f, \text { in,avg }}\right)$. For two-phase flow, the reference temperature is defined as the local saturation temperature of the two-phase mixture at the location of the wall temperature measurement, $T_{\text {ref,avg }}=T_{\text {sat,avg. }}$. A local saturation pressure is calculated assuming a linear decrease in the pressure from the inlet to the outlet of the microchannel: $p_{\text {sat }}=p_{\text {in }}-\left(z / L_{\text {heated }}\right)\left(p_{\text {in }}\right.$ - $\left.p_{\text {out }}\right)$. The time-averaged wall superheat is calculated using $\Delta T_{\text {wall,sup,avg }}=T_{\text {wall,avg }}-T_{\text {ref,avg. }}$

The instantaneous mass flux through the test section is calculated using $G=Q \rho /\left(\pi D^{2} / 4\right)$ where $Q$ is the measured volumetric flow rate and $\rho$ is the calculated liquid density corresponding to the measured liquid temperature at the flow meter. The pressure drop across the test section is calculated as the difference between the test section inlet and outlet pressures, $\Delta p=p_{\text {in }}-p_{\text {out }}$ 


\section{Results and discussion}

\subsection{Time-averaged characterization during constant heating conditions}

Figure 2 shows the time-averaged (a) wall superheat, (b) heat transfer coefficient, (c) pressure drop, and (d) mass flux as a function of time-averaged heat flux under constant heating

conditions. At $q_{\text {net,avg }} \leq 29.7 \mathrm{~kW} / \mathrm{m}^{2}$, single-phase flow is observed in the microchannel (denoted with open symbols in Figure 2) whereas at $q_{\text {net,avg }}>29.7 \mathrm{~kW} / \mathrm{m}^{2}$, boiling is observed (denoted with closed symbols in Figure 2). The trends with increasing heat flux in the single-phase flow regime are as expected; the wall superheat increases linearly (Figure 2a), which corresponds to an approximately constant heat transfer coefficient (Figure 2b), and the pressure drop (Figure 2c) and mass flux (Figure 2d) are nearly constant. 

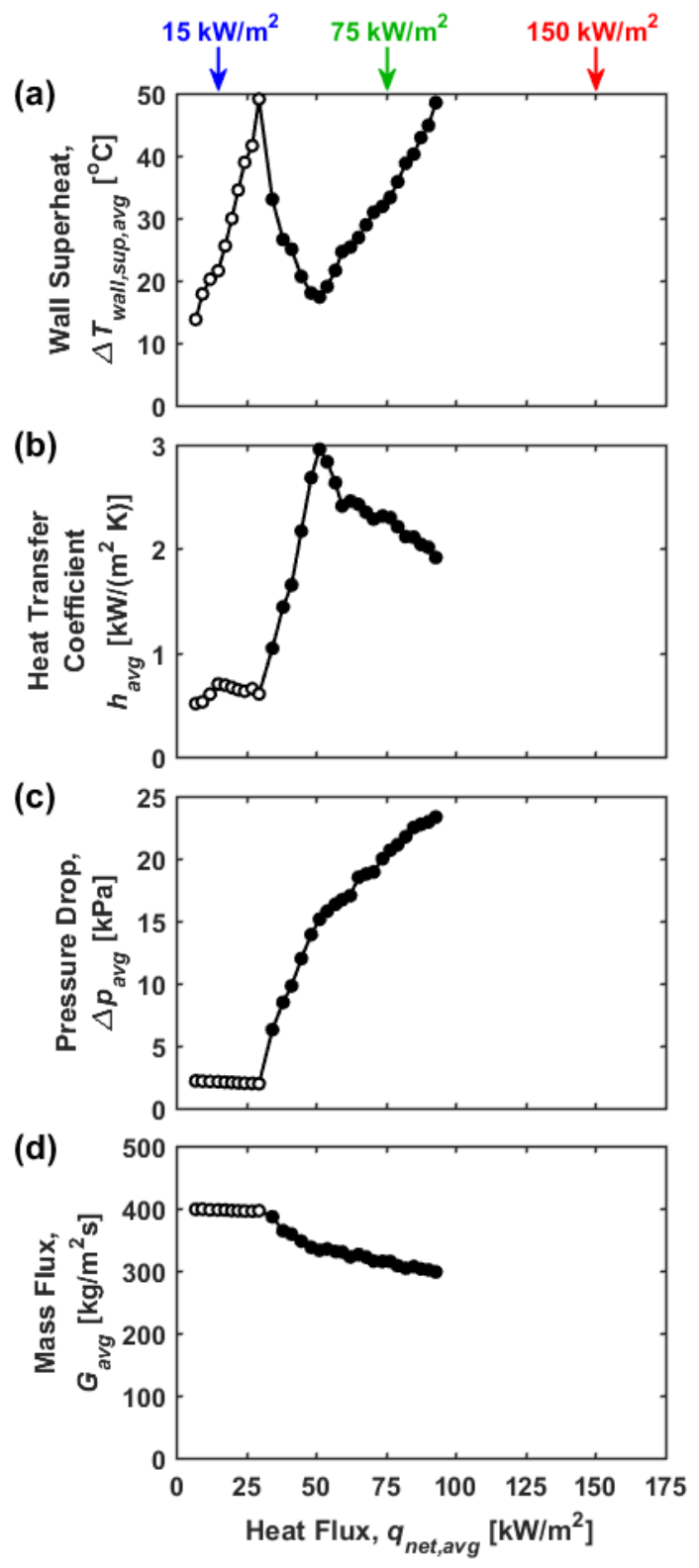

Figure 2. Time-averaged (a) wall superheat, (b) heat transfer coefficient, (c) pressure drop, and (d) mass flux as a function of time-averaged heat flux under constant heating conditions. Open symbols denote observation of a single-phase flow regime and closed symbols denote flow boiling. Three select heat fluxes of $q_{\text {net,avg }}=15,75$, and $150 \mathrm{~kW} / \mathrm{m}^{2}$ are noted, which respectively correspond to single-phase flow, flow boiling, and a very high heat flux above critical heat flux that is unobtainable under constant heating conditions. 
Once boiling is observed $\left(q_{\text {net, avg }}>29.7 \mathrm{~kW} / \mathrm{m}^{2}\right)$, the wall superheat reduces with increasing heat flux until it reaches a local minimum of $T_{\text {wall, avg }}=17.6{ }^{\circ} \mathrm{C}$ at $q_{\text {net,avg }}=51.3$ $\mathrm{kW} / \mathrm{m}^{2}$, after which it begins to increase. This trend in the wall superheat is correlated to the heat transfer coefficient, which increases with increasing heat flux once the fluid is boiling until it reaches a maximum of $h_{\text {avg }}=3.0 \mathrm{~kW} /\left(\mathrm{m}^{2} \mathrm{~K}\right)$ at $q_{\text {net, } \text { avg }}=51.3 \mathrm{~kW} / \mathrm{m}^{2}$, after which it begins to decrease. For the first five heat flux measurements that cause boiling $\left(29.7<q_{\text {net, avg }} \leq 51.3\right.$ $\mathrm{kW} / \mathrm{m}^{2}$ ), the flow periodically transitions between single-phase flow and two-phase flow throughout the $12 \mathrm{~s}$ data collection period. Throughout this span of heat inputs, the percentage of time spent in the two-phase flow regime increases monotonically with increasing heat flux, resulting in a lower time-averaged wall superheat and a higher time-averaged heat transfer coefficient. For $q_{\text {net,avg }} \geq 51.3 \mathrm{~kW} / \mathrm{m}^{2}$, boiling is always occurring in the channel, and the observed increase in the wall superheat and decrease in the heat transfer coefficient correlates to an increase in the vapor quality. The trend and values of the two-phase heat transfer coefficient shown in Figure $2 \mathrm{~b}$ agree quite well with those predicted using the correlation by Bertsch et al. [21]. The hydrodynamic trends throughout the boiling region $\left(q_{n e t, a v g}>29.7 \mathrm{~kW} / \mathrm{m}^{2}\right)$ are as expected, a monotonic increase in the time-averaged pressure drop due to an increased accelerational pressure drop, and a monotonic decrease in the time-averaged mass flux through the channel, due to the increased flow resistance.

This study focuses on the effect of transient heating conditions on flow boiling performance. Of specific interest are pulses between vastly different heat flux levels that may cause flow regime transitions or other dynamic behaviors affecting the performance. For purposes of studying such transient pulses, three different heat flux levels were selected based on the time-averaged data shown in Figure 2 to exhibit highly contrasting flow conditions: a low 
heat flux corresponding to single-phase flow $\left(q_{\text {net,avg }}=15 \mathrm{~kW} / \mathrm{m}^{2}\right)$, an intermediate heat flux corresponding to continuous flow boiling $\left(q_{\text {net, avg }}=75 \mathrm{~kW} / \mathrm{m}^{2}\right)$, and a very high heat flux which exceeds critical heat flux and would result in dryout if applied continuously $\left(q_{\text {net,avg }}=150\right.$ $\mathrm{kW} / \mathrm{m}^{2}$ ). These three selected heat flux levels are illustrated relative to the time-averaged heat transfer and hydrodynamic behavior in Figure 2.

\subsection{Thermal time constant}

The thermal time constant of the test section microchannel is characterized to help interpret its thermal response when subjected to the transient heating conditions. The thermal time constant of the microchannel under single-phase flow conditions was experimentally determined by applying a step change in the power level applied to the ITO coating from $0.4 \mathrm{~W}$ to $2 \mathrm{~W}$, and measuring the time needed for the wall temperature response to reach $(1-1 / e) \approx$ $63.2 \%$ of the steady wall temperature. These two heat flux levels were used, in combination with the flow conditions listed in Section 2.2, because they allowed the flow to remain in the single-phase regime. This average experimental thermal time constant was measured to be $\tau_{\exp }=$ $0.43 \pm 0.02 \mathrm{~s}$, as shown in Figure S1 in the Supplementary Materials.

The thermal time constant of the test section microchannel is also theoretically estimated as $\tau_{\text {theory }}=\rho c_{p} L_{c} / h$ where $\rho$ and $c_{p}$ are the density and specific heat of the borosilicate glass, $L_{c}$ is the characteristic length of the microchannel (defined in this study as the microchannel wall thickness, $100 \mu \mathrm{m}$ ), and $h$ is the heat transfer coefficient [22]. The single-phase heat transfer coefficient measured during the quantification of the experimental thermal time constant $(h=$ $0.55 \mathrm{~kW} / \mathrm{m}^{2} \mathrm{~K}$ ) was used to calculate a theoretical thermal time constant of $\tau_{\text {theory }}=0.34 \mathrm{~s}$, which is in good agreement with the measured thermal time constant. Because the thermal time 
constant is inversely dependent on the heat transfer coefficient, it is expected to reduce under conditions of flow boiling, for which there is a higher heat transfer coefficient (Figure 2b).

\subsection{Characterization during transient heating conditions}

Four different operating scenarios (i.e., combinations of initial and pulsed heat flux levels) are obtainable based on the three selected heat flux levels, as shown in Table 1. Note that the heat flux cannot initially be constant at $150 \mathrm{~kW} / \mathrm{m}^{2}$ because it exceeds critical heat flux and would result in dryout if applied continuously; this heat flux level can only be sustained for brief time periods as a pulsed value. For operating scenarios 1 and 2, where the initial and pulsed heat fluxes switch between $15 \mathrm{~kW} / \mathrm{m}^{2}$ and $75 \mathrm{~kW} / \mathrm{m}^{2}$, the pulse durations range from 0 to $10 \mathrm{~s}$. This range spans conditions with no heat flux pulse ( $0 \mathrm{~s}$ pulse duration) to effectively a step change in the heat flux level because the pulse duration is over an order of magnitude larger than the thermal time constant $\left(\tau_{\exp }=0.43 \mathrm{~s}\right)$ and the flow reaches a new steady-state condition by the end of the $10 \mathrm{~s}$ pulse. For operating scenarios 3 and 4 , where the heat flux is pulsed to $150 \mathrm{~kW} / \mathrm{m}^{2}$, the pulse duration was increased from zero in $0.05 \mathrm{~s}$ increments until the wall temperature measured during the transient event neared a limit of $200{ }^{\circ} \mathrm{C}$ (which corresponded to pulse durations of 0.35 and $0.50 \mathrm{~s}$ for operating scenarios 3 and 4 , respectively). To illustrate the dynamic response to a transient heat flux pulse, the maximum pulse duration tested for each of the four operating scenarios will be shown in Figures 3-6. Results for several shorter pulse durations for each operating scenario are available online in the Supplementary Materials. 
Table 1. Operating scenarios and pulse durations used in this study to perform the transient heating tests.

\begin{tabular}{cccc}
\hline $\begin{array}{c}\text { Operating } \\
\text { Scenario }\end{array}$ & $\begin{array}{c}\text { Initial Heat } \\
\text { Flux }\left[\mathrm{kW} / \mathrm{m}^{2}\right]\end{array}$ & $\begin{array}{c}\text { Pulsed Heat } \\
\text { Flux }\left[\mathrm{kW} / \mathrm{m}^{2}\right]\end{array}$ & Pulse Durations $[\mathrm{s}]$ \\
\hline 1 & 15 & 75 & $0-0.50^{*}, 0.75,1,2,4,6,8,10$ \\
\hline 2 & 75 & 15 & $0-0.50^{*}, 0.75,1,2,4,6,8,10$ \\
\hline 3 & 15 & 150 & $0-0.35^{*}$ \\
\hline 4 & 75 & 150 & $0-0.50^{*}$ \\
\hline
\end{tabular}

* Increments of $0.05 \mathrm{~s}$

Figure 3a shows the heat flux, wall temperature, pressure drop, and mass flux as a function of time for the heat flux pulse from 15 to $75 \mathrm{~kW} / \mathrm{m}^{2}$. At $t=0 \mathrm{~s}$ (start of the pulse), the wall temperature increases quickly until it reaches $105^{\circ} \mathrm{C}$ at $t=0.172 \mathrm{~s}$, which causes the fluid inside the microchannel to boil. Once boiling has started, the wall temperature remains fairly steady until approximately $t=0.5 \mathrm{~s}$, at which point it begins to increase again until it reaches a maximum wall temperature of $120^{\circ} \mathrm{C}$ at $t=0.688 \mathrm{~s}$. Thereafter, the wall temperature slowly decreases until it assumes time-periodic behavior after approximately $t=3 \mathrm{~s}$. It is important to note that during this transition from constant heating at 15 to $75 \mathrm{~kW} / \mathrm{m}^{2}$, the wall temperature spikes approximately $20{ }^{\circ} \mathrm{C}$ higher than the time-averaged wall temperature observed at 75 $\mathrm{kW} / \mathrm{m}^{2}$ at $t>3 \mathrm{~s}$. This result demonstrates the critical potential effects of transient changes in heating conditions on flow boiling performance, which can induce wall temperature excursions during flow transition events that exceed the bounding limits expected of steady performance.

As seen for the wall temperature, the onset of boiling also causes a dynamic response in the pressure drop and mass flux before transitioning to a time-periodic condition at $t>3 \mathrm{~s}$, where there are abrupt, time-periodic spikes in the pressure drop and corresponding dips in the mass flux. These result from the pressure drop instability that occurs during boiling due to the interaction between vapor within the channel and the compressible volume upstream of the test 
section. An exhaustive characterization and discussion of the pressure drop instability during constant heating conditions was provided in Ref. [4]. 


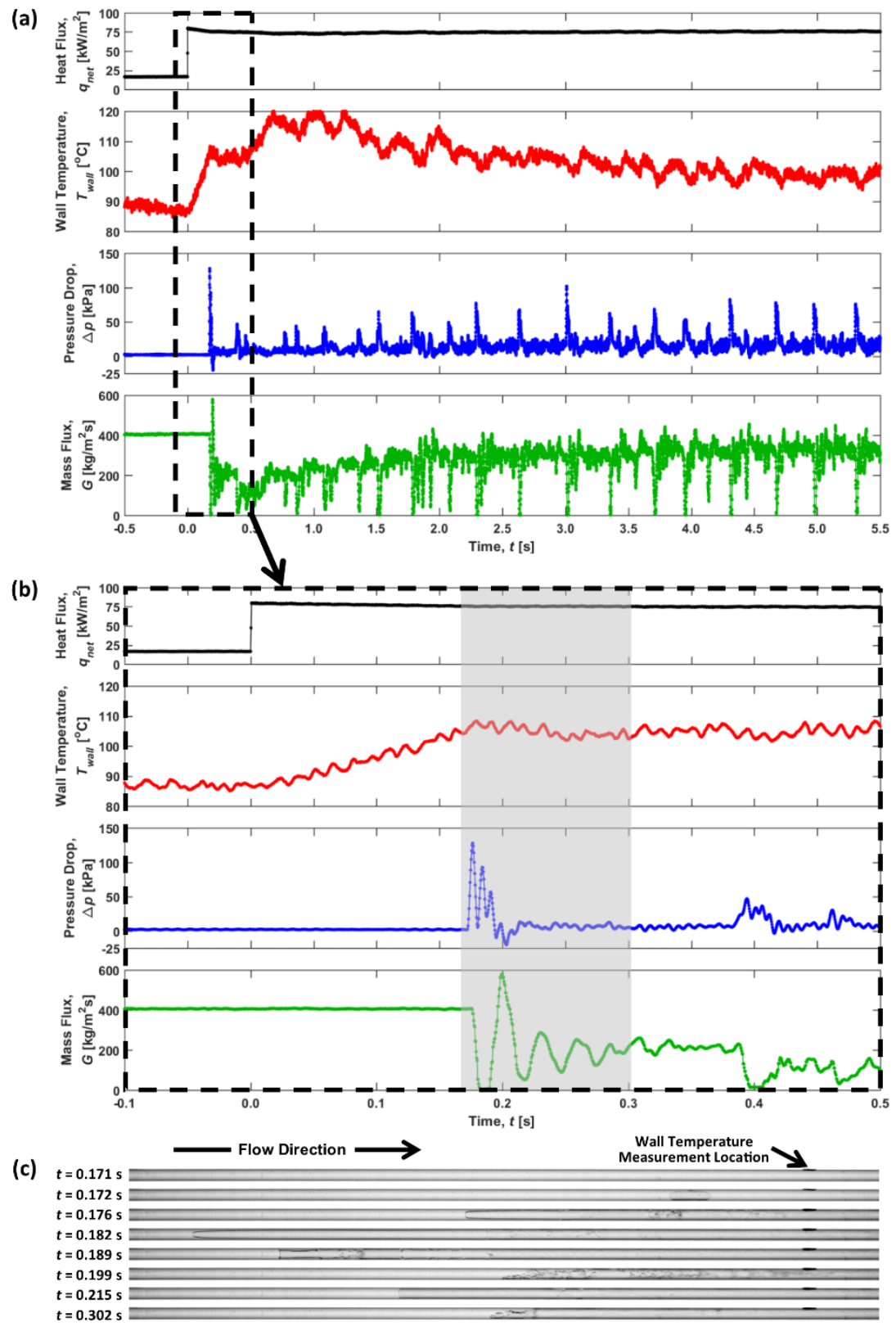

Figure 3. Synchronized measurements of heat flux, wall temperature, pressure drop, and mass flux as a function of time for (a) -0.5 to $5.5 \mathrm{~s}$ and (b) -0.1 to $0.5 \mathrm{~s}$ relative to the start of a $10 \mathrm{~s}$ heat flux pulse from 15 to $75 \mathrm{~kW} / \mathrm{m}^{2}$ (operating scenario 1). (c) Selected images of the twophase morphology are shown that correspond to the time period indicated by the gray box in (b). A corresponding video of the synchronized flow visualization and sensor measurements is available online in the Supplementary Materials (Video S1). 
Further investigation into the pressure drop, mass flux, and two-phase morphology immediately after the onset of boiling reveals the dynamic response of the system. Shown in Figure $3 \mathrm{~b}$ are the sensor measurements immediately before and after the heat flux pulse at $t=0 \mathrm{~s}$. A series of selected images obtained with the high-speed camera from $t=0.171 \mathrm{~s}$ to $0.302 \mathrm{~s}$ are shown in Figure 3c, which correspond to the gray shaded region in Figure 3b. The flow direction in Figure $3 \mathrm{c}$ is from left to right. The entire heated length of the microchannel $\left(L_{\text {heated }} /\right.$ $D=84$ ) is shown in the frame; the electrical connections to the ITO coating are just outside the viewing region. The small black dot visible in each image, on the top portion of the channel near the outlet, is the location of the wall temperature measurement. Immediately following vapor bubble nucleation from the microchannel wall at $t=0.172 \mathrm{~s}$, a large spike in the pressure drop to $\sim 128 \mathrm{kPa}$ and a corresponding reduction in the mass flux to zero is observed. This pressure drop spike results from explosive-like growth of the vapor bubble, a characteristic of the rapid-bubblegrowth instability at the onset of boiling [3], which can be magnified when using highly wetting working fluids and smooth microchannel surfaces such as those in this study. Rapid bubble growth within the channel results in local flow reversal, as shown in Figure $3 \mathrm{c}$ from $t=0.172 \mathrm{~s}$ to $0.182 \mathrm{~s}$, and pressurization of the upstream compressible volume. The pressure drop then reduces and is followed by a surge in the mass flux to $579 \mathrm{~kg} / \mathrm{m}^{2} \mathrm{~s}$ (well above the initial mass flux of $400 \mathrm{~kg} / \mathrm{m}^{2}$ s during single-phase flow) due to depressurization of the upstream compressible volume, which pushes the vapor in the channel downstream, as shown in Figure $3 \mathrm{c}$ at $t=0.189$ and $0.199 \mathrm{~s}$. Oscillations in the pressure drop, mass flux, and two-phase morphology are observed thereafter, which decay in magnitude over time and eventually transition to the time-periodic boiling conditions described above and shown in Figure 3a after approximately $t=$ $3 \mathrm{~s}$. The time required to reach time-periodic boiling conditions $(\sim 3 \mathrm{~s})$ is an order of magnitude 
larger than the experimentally-obtained thermal time constant of the microchannel under singlephase flow conditions $(0.43 \mathrm{~s})$. This suggests that the dynamic response to boiling is dictated by the thermal-fluidic behavior of the system, and cannot be simply attributed to the thermal capacity of the microchannel when subjected to the transient heat load. The oscillatory behavior immediately following the onset of boiling is qualitatively similar to the dynamic response of an underdamped mass-spring-damper system subjected to a unit step input. This response is due to the complex interaction between the inertia of the flow, upstream compressibility, and vapor within the channel, which to date is poorly understand. Observing and quantifying the dynamic response during this transient event provides new insights into the governing mechanisms that may lead to predictive mechanistic modeling capabilities.

Operating scenario 2 probes the transient response during a transition from two-phase flow to single-phase flow. Figure 4a shows the heat flux, wall temperature, pressure drop, and mass flux as a function of time for the heat flux pulse from 75 to $15 \mathrm{~kW} / \mathrm{m}^{2}$. Prior to the start of the pulse, the fluid in the channel is boiling and the pressure drop instability is occurring, resulting in time-periodic fluctuations in the wall temperature, pressure drop, and mass flux. Time-periodic oscillations in the vapor front, which moves upstream and downstream in the channel as shown in Figure $4 \mathrm{~b}$ from $t=-0.113$ to $0 \mathrm{~s}$, are characteristic of the pressure drop instability. At $t=0 \mathrm{~s}$ (start of the pulse), the wall temperature decreases and the vapor front moves downstream (Figure $4 \mathrm{~b} ; t=0$ to $0.348 \mathrm{~s}$ ). During this time period, there is a continual reduction in the pressure drop and a corresponding increase in the mass flux through the channel, as shown in Figure 4a. Once the vapor moves downstream of the location of the wall temperature measurement (which occurs at $t=0.339 \mathrm{~s}$ ), the wall temperature begins to rise until it reaches $90{ }^{\circ} \mathrm{C}$; this correlates to the reduced heat transfer coefficient for single-phase flow 
relative to two-phase flow at a given heat flux level. Similar to the onset of boiling, when the flow transitions from two-phase to single-phase flow, the wall temperature does not monotonically transition from one operating condition to another, but instead undershoots its eventual operating point and features a larger thermal fluctuation during this transient event.

(a)
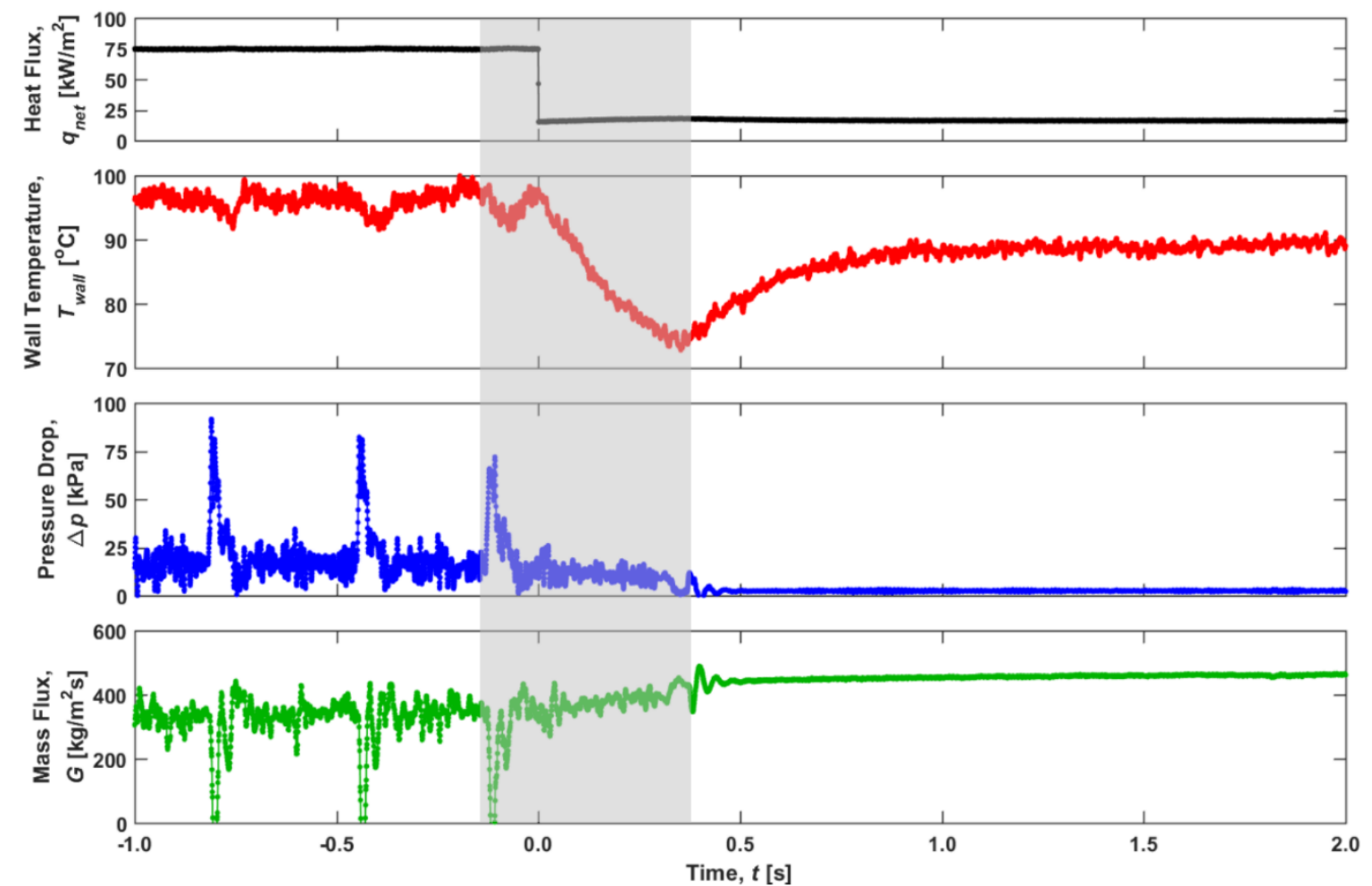

(b)

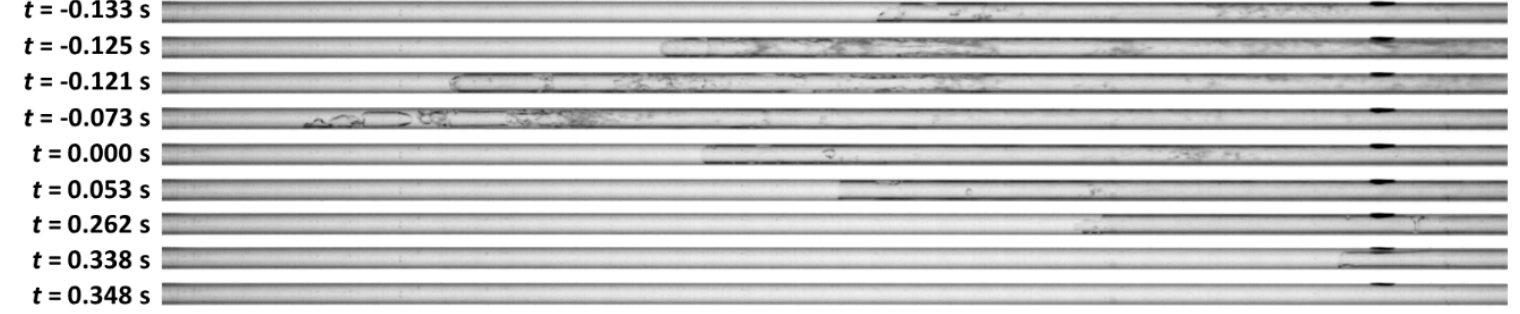

Figure 4. (a) Synchronized measurements of heat flux, wall temperature, pressure drop, and mass flux as a function of time for -1 to 2 s relative to the start of a $10 \mathrm{~s}$ heat flux pulse from 75 to 15 $\mathrm{kW} / \mathrm{m}^{2}$ (operating scenario 2). (b) Selected images of the two-phase morphology are shown that correspond to the time period indicated by the gray box in (a). A corresponding video of the 
synchronized flow visualization and sensor measurements is available online in the Supplementary Materials (Video S2).

In many applications, short high-heat-flux pulses are encountered that exceed the heat fluxes that could be sustained by the cooling system during steady operation. It is vitally important to quantify the response of the cooling system to these transient heat flux pulse events, to assess the system's tolerance to these excursions. Figure 5a shows the heat flux, wall temperature, pressure drop, and mass flux as a function of time for a $0.35 \mathrm{~s}$ heat flux pulse from 15 to $150 \mathrm{~kW} / \mathrm{m}^{2}$. Prior to the pulse, the wall temperature, pressure drop, and mass flux are steady and the flow is single-phase. Once the pulse begins, the wall temperature increases until fluid in the channel begins boiling near the outlet (Figure $5 \mathrm{~b} ; t=0.047 \mathrm{~s}$ ). Nucleation of a vapor bubble causes a large pressure spike within the channel, leading to a sharp reduction in the mass flux. The high heat flux causes the vapor within the channel to expand quickly and move upstream until most of the channel is full of vapor (Figure $5 \mathrm{~b} ; t=0.178 \mathrm{~s}$ ). An underdamped dynamic response, similar to that noted in Figure 3, can be observed in the flow visualizations and sensor measurement between approximately $t=0.04 \mathrm{~s}$ and $0.1 \mathrm{~s}$. While the heat flux is pulsed, the expanding vapor within the channel induces a large flow resistance which causes the mass flux through the channel to be extremely low $\left(<100 \mathrm{~kg} / \mathrm{m}^{2} \mathrm{~s}\right)$ and the wall temperature to rise. A thin liquid layer is observed to remain wetted on the microchannel wall, which suggests that the temperature rise is due to a lack of incoming liquid that suppresses the forced convective boiling heat transfer mechanism; it is not due to dryout (i.e., vapor contacting the heated wall). After the heat flux pulse ends at $t=0.35 \mathrm{~s}$, the wall temperature, pressure drop, mass flux gradually return to their initial levels before the pulse and vapor is no longer present in the channel. At $t=1.5 \mathrm{~s}$, an inflection point in the reducing wall temperature is observed, 
corresponding to a local change in the two-phase morphology near the location of the wall temperature measurement. Specifically, the liquid annulus adjacent to the wall thickens, which could allow for bubble nucleation and changes in the heat transfer mechanisms.

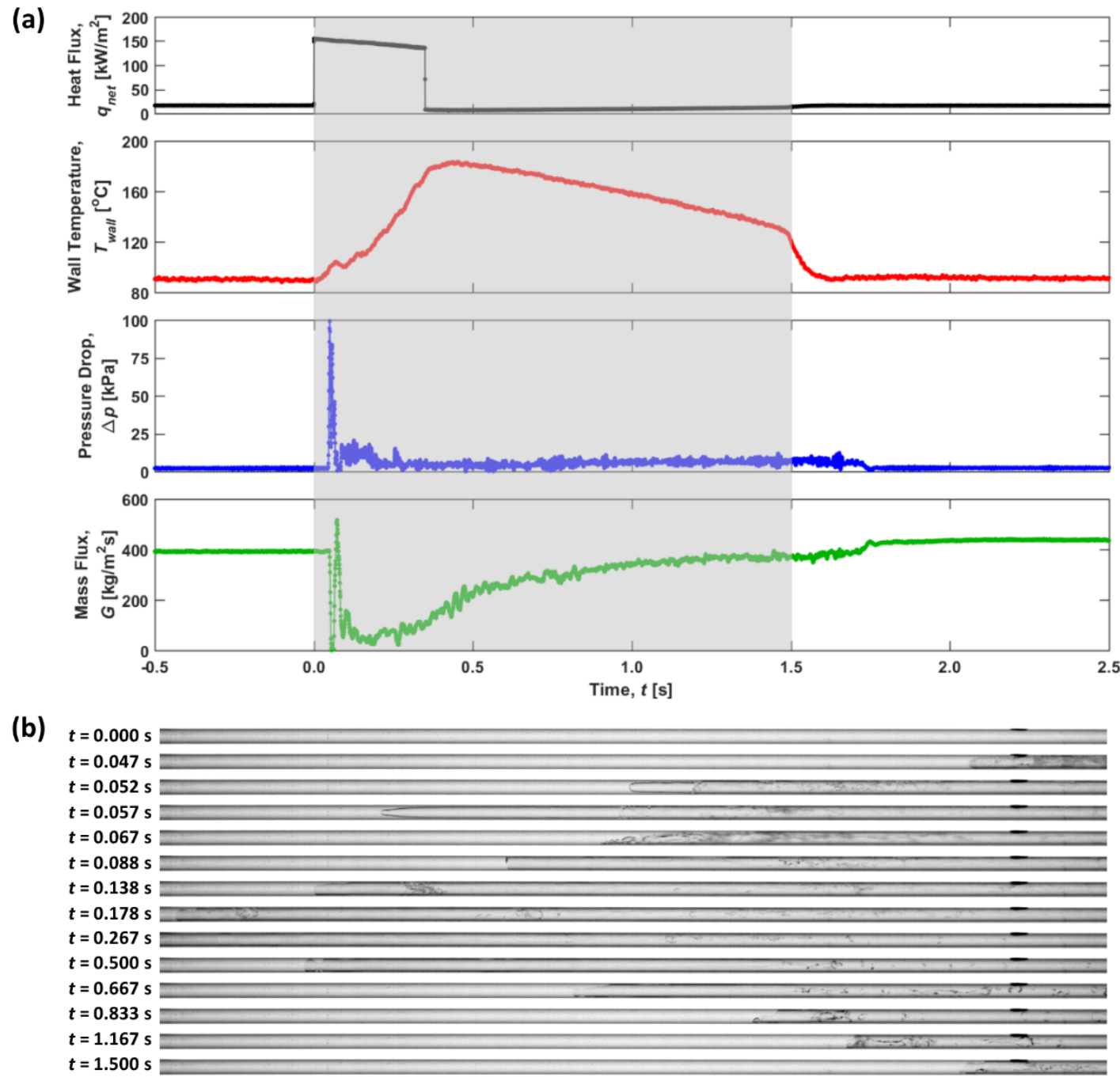

Figure 5. (a) Synchronized measurements of heat flux, wall temperature, pressure drop, and mass flux as a function of time for -0.5 to $2.5 \mathrm{~s}$ relative to the start of a $0.35 \mathrm{~s}$ heat flux pulse from 15 to $150 \mathrm{~kW} / \mathrm{m}^{2}$ (operating scenario 3). (b) Selected images of the two-phase morphology are shown that correspond to the time period indicated by the gray box in (a). A corresponding video of the synchronized flow visualization and sensor measurements is available online in the Supplementary Materials (Video S3). 
Figure 6a shows the heat flux, wall temperature, pressure drop, and mass flux as a function of time for a $0.5 \mathrm{~s}$ heat flux pulse from 75 to $150 \mathrm{~kW} / \mathrm{m}^{2}$. Prior to the pulse, from $t=-0.5$ to $0 \mathrm{~s}$, the fluid in the channel is boiling and there are time-periodic pressure drop oscillations. The frequency of these oscillations is $4 \mathrm{~Hz}$, as determined through spectral analysis of the sensor measurements using a fast Fourier transform. When the pulse begins at $t=0 \mathrm{~s}$, the wall temperature begins to rise and the vapor front within the channel moves upstream until it is very close to the entrance of the heated region, as shown in Figure $6 \mathrm{~b}$ at $t=0.279 \mathrm{~s}$. Throughout the pulse, time-periodic fluctuations in the pressure drop and mass flux measurements are again observed, but the frequency of the oscillations is significantly increased to $29 \mathrm{~Hz}$. The increased frequency is due to the vapor front being located near the channel inlet, reducing the axial distance that the vapor front needs to travel to move upstream into the inlet plenum during the pressure drop oscillations. One cycle of the time-periodic two-phase morphology observed during the high-frequency pressure drop oscillations that occur during the heat flux pulse is shown in Figure 6b, and is indicated by the gray box in Figure 6a; this oscillatory behavior is clearly observable in Supplementary Video S4. It is worth noting that a $150 \mathrm{~kW} / \mathrm{m}^{2}$ heat flux pulse is sustained for $0.5 \mathrm{~s}$ with a wall temperature below the $200{ }^{\circ} \mathrm{C}$ limit when boiling was initially occurring within the channel at $q_{n e t}=75 \mathrm{~kW} / \mathrm{m}^{2}$, whereas only a 0.35 s pulse could be sustained when the flow was initially single-phase at $q_{\text {net }}=15 \mathrm{~kW} / \mathrm{m}^{2}$. This occurs despite the wall temperature being slightly higher for the initially boiling scenario than for the initially single-phase flow scenario. 
(a)
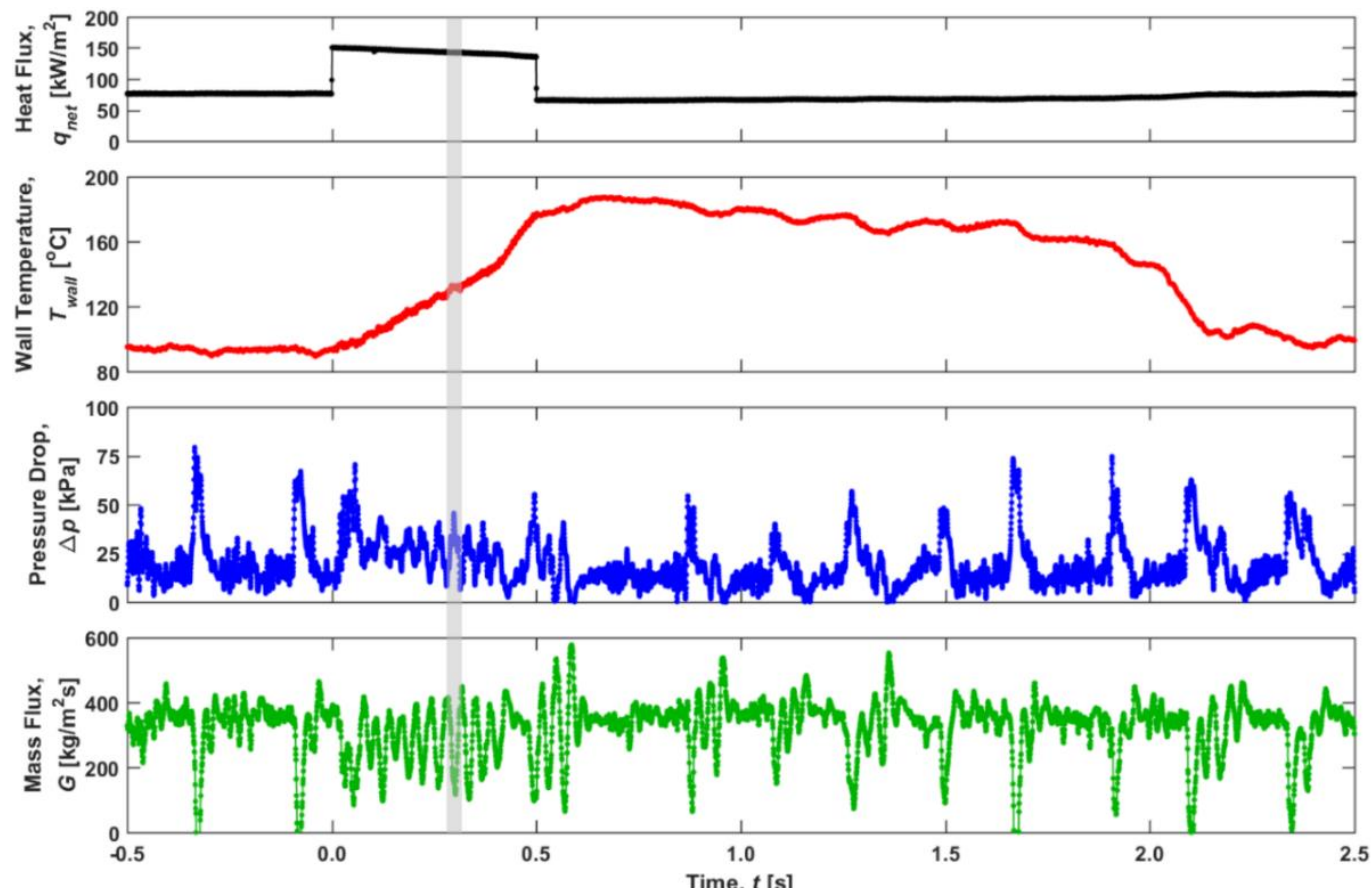

(b) $t=0.279 \mathrm{~s}$

$t=0.289$

$t=0.300 \mathrm{~s}$

$t=0.308 \mathrm{~s}$

$t=0.313 \mathrm{~s}$

Figure 6. (a) Synchronized measurements of heat flux, wall temperature, pressure drop, and mass flux as a function of time for -0.5 to $2.5 \mathrm{~s}$ relative to the start of a $0.5 \mathrm{~s}$ heat flux pulse from 75 to $150 \mathrm{~kW} / \mathrm{m}^{2}$ (operating scenario 4). (b) Selected images of the two-phase morphology are shown that correspond to the time period indicated by the gray box in (a). A corresponding video of the synchronized flow visualization and sensor measurements is available online in the

Supplementary Materials (Video S4).

\section{Conclusions}

The dynamic response of microchannel flow boiling to a single heat flux pulse was experimentally investigated in this study. A heat flux applied to the ITO layer on the channel enabled transient heating simultaneous with high-speed flow visualization of the two-phase 
morphology and high-frequency measurement of the wall temperature, pressure drop, and mass flux. Three different heat flux levels which result in highly contrasting flow conditions were selected based on the time-averaged data, namely $q_{n e t}=15,75$, and $150 \mathrm{~kW} / \mathrm{m}^{2}$, which respectively correspond to single-phase flow, continuous two-phase flow, and above critical heat flux. Four different operating scenarios are possible for pulsed heating tests based on the three selected heat flux levels. The pulse duration was incremented for each operating scenario until either a steady condition was achieved during the pulse or the wall temperature reached the temperature limit. At the onset of boiling, the dynamic response resembled that of an underdamped mass-spring-damper system subjected to a unit step input. In general, any step up/down in the heat flux level that induces/arrests boiling is seen to cause the temperature to temporarily over/under-shoot the eventual steady temperature. A high-heat-flux pulse applied to a channel with single-phase flow induces boiling and causes a large temperature spike due to a significant reduction in incoming flow rate and rapid evaporation. This high-heat-flux pulse applied to a channel already experiencing time-periodic boiling conditions significantly increases the characteristic frequency of a pressure drop instability. A longer duration high-heat-flux pulse can be withstood when applied to a channel with time-periodic boiling, compared to one with single-phase flow, despite being at an initially higher heat flux and wall temperature prior to the pulse.

\section{Acknowledgments}

This research was sponsored by the Naval Engineering Education Consortium (NEEC), with support of Naval Surface Warfare Center (NSWC) Crane Division in Crane, Indiana. Special thanks to Dr. Brian D. Olson (NSWC Crane Division) for technical discussion of this work. 


\section{Appendix A. Supplementary material}

Supplementary material associated with this article can be found in the online version.

\section{References}

[1] S.R. Rao, F. Houshmand, Y. Peles, Transient flow boiling heat-transfer measurements in microdomains, International Journal of Heat and Mass Transfer, 76 (2014) 317-329.

[2] Y. Zhu, D.S. Antao, D.W. Bian, S.R. Rao, J.D. Sircar, T. Zhang, E.N. Wang, Suppressing high-frequency temperature oscillations in microchannels with surface structures, Applied Physics Letters, 110(3) (2017) 033501.

[3] T.A. Kingston, J.A. Weibel, S.V. Garimella, High-frequency thermal-fluidic characterization of dynamic microchannel flow boiling instabilities: Part 1 - Rapidbubble-growth instability at the onset of boiling, International Journal of Multiphase Flow, 106 (2018) 179-188.

[4] T.A. Kingston, J.A. Weibel, S.V. Garimella, High-frequency thermal-fluidic characterization of dynamic microchannel flow boiling instabilities: Part 2 - Impact of operating conditions on instability type and severity, International Journal of Multiphase Flow, 106 (2018) 189-201.

[5] S. Bigham, S. Moghaddam, Microscale study of mechanisms of heat transfer during flow boiling in a microchannel, International Journal of Heat and Mass Transfer, 88 (2015) 111-121.

[6] S. Bigham, S. Moghaddam, Role of bubble growth dynamics on microscale heat transfer events in microchannel flow boiling process, Applied Physics Letters, 107(24) (2015) 244103.

[7] T. David, D. Mendler, A. Mosyak, A. Bar-Cohen, G. Hetsroni, Thermal management of time-varying high heat flux electronic devices, Journal of Electronic Packaging, 136(2) (2014) 021003. 
[8] C.G. Tua, T. Pratt, A.I. Zaghloul, A study of interpulse instability in gallium nitride power amplifiers in multifunction radars, IEEE Transactions on Microwave Theory and Techniques, 64(11) (2016) 3732-3747.

[9] A. Bar-Cohen, Gen-3 thermal management technology: role of microchannels and nanostructures in an embedded cooling paradigm, Journal of Nanotechnology in Engineering and Medicine, 4(2) (2013) 020907.

[10] L.J. Guo, Z.P. Feng, X.J. Chen, Transient convective heat transfer of steam-water twophase flow in a helical tube under pressure drop type oscillations, International Journal of Heat and Mass Transfer, 45(3) (2002) 533-542.

[11] I.W. Park, J. Ryu, M. Fernandino, C.A. Dorao, Can flow oscillations during flow boiling deteriorate the heat transfer coefficient?, Applied Physics Letters, 113(15) (2018).

[12] M. Sorum, C.A. Dorao, Experimental study of the heat transfer coefficient deterioration during density wave oscillations, Chemical Engineering Science, 132 (2015) 194-201.

[13] M. Ozawa, H. Umekawa, K. Mishima, T. Hibiki, Y. Saito, CHF in oscillatory flow boiling channels, Chemical Engineering Research and Design, 79(A4) (2001) 389-401.

[14] S. Basu, B. Werneke, Y. Peles, M.K. Jensen, Transient microscale flow boiling heat transfer characteristics of HFE-7000, International Journal of Heat and Mass Transfer, 90 (2015) 396-405.

[15] H. Huang, N. Borhani, J. Thome, Thermal response of multi-microchannel evaporators during flow boiling of refrigerants under transient heat loads with flow visualization, Journal of Electronic Packaging, 138(3) (2016) 031004.

[16] G. Chen, P. Cheng, Nucleate and film boiling on a microheater under pulse heating in a microchannel, International Communications in Heat and Mass Transfer, 36(5) (2009) 391-396.

[17] T.A. Kingston, J.A. Weibel, S.V. Garimella, Time-resolved characterization of microchannel flow boiling during transient heating: Part 2 - Dynamic reponse to timeperiodic heat flux pulses, International Journal of Heat and Mass Transfer (in review). 
[18] T.A. Kingston, J.A. Weibel, S.V. Garimella, Ledinegg instability-induced temperature excursion between thermally isolated, heated parallel microchannels, International Journal of Heat and Mass Transfer, 132 (2019) 550-556.

[19] K.P. Drummond, D. Back, M.D. Sinanis, D.B. Janes, D. Peroulis, J.A. Weibel, S.V. Garimella, A hierarchical manifold microchannel heat sink array for high-heat-flux twophase cooling of electronics, International Journal of Heat and Mass Transfer, 117 (2018) 319-330.

[20] K.P. Drummond, D. Back, M.D. Sinanis, D.B. Janes, D. Peroulis, J.A. Weibel, S.V. Garimella, Characterization of hierarchical manifold microchannel heat sink arrays under simultaneous background and hotspot heating conditions, International Journal of Heat and Mass Transfer, 126 (2018) 1289-1301.

[21] S.S. Bertsch, E.A. Groll, S.V. Garimella, A composite heat transfer correlation for saturated flow boiling in small channels, International Journal of Heat and Mass Transfer, 52(7) (2009) 2110-2118.

[22] T.L. Bergman, F.P. Incropera, D.P. DeWitt, A.S. Lavine, Fundamentals of Heat and Mass Transfer, Wiley, 2011. 